\title{
Structure and Function of the Acetylpolyamine Amidohydrolase from the Deep Earth Halophile Marinobacter subterrani
}

Jeremy D. Osko, ${ }^{\dagger}$ Benjamin W. Roose,$^{\dagger}$ Stephen A. Shinsky, ${ }^{\dagger, \downarrow}$ and David W. Christianson ${ }^{\dagger, *}$

${ }^{\dagger}$ Roy and Diana Vagelos Laboratories, Department of Chemistry, University of Pennsylvania, 231 South $34^{\text {th }}$ Street, Philadelphia, PA 19104-6323, United States

${ }^{\ddagger}$ Current Address: Department of Biology, The College of New Jersey, 2000 Pennington Road, Ewing, NJ 08618, United States

*author to whom correspondence should be sent: E-mail chris@sas.upenn.edu 

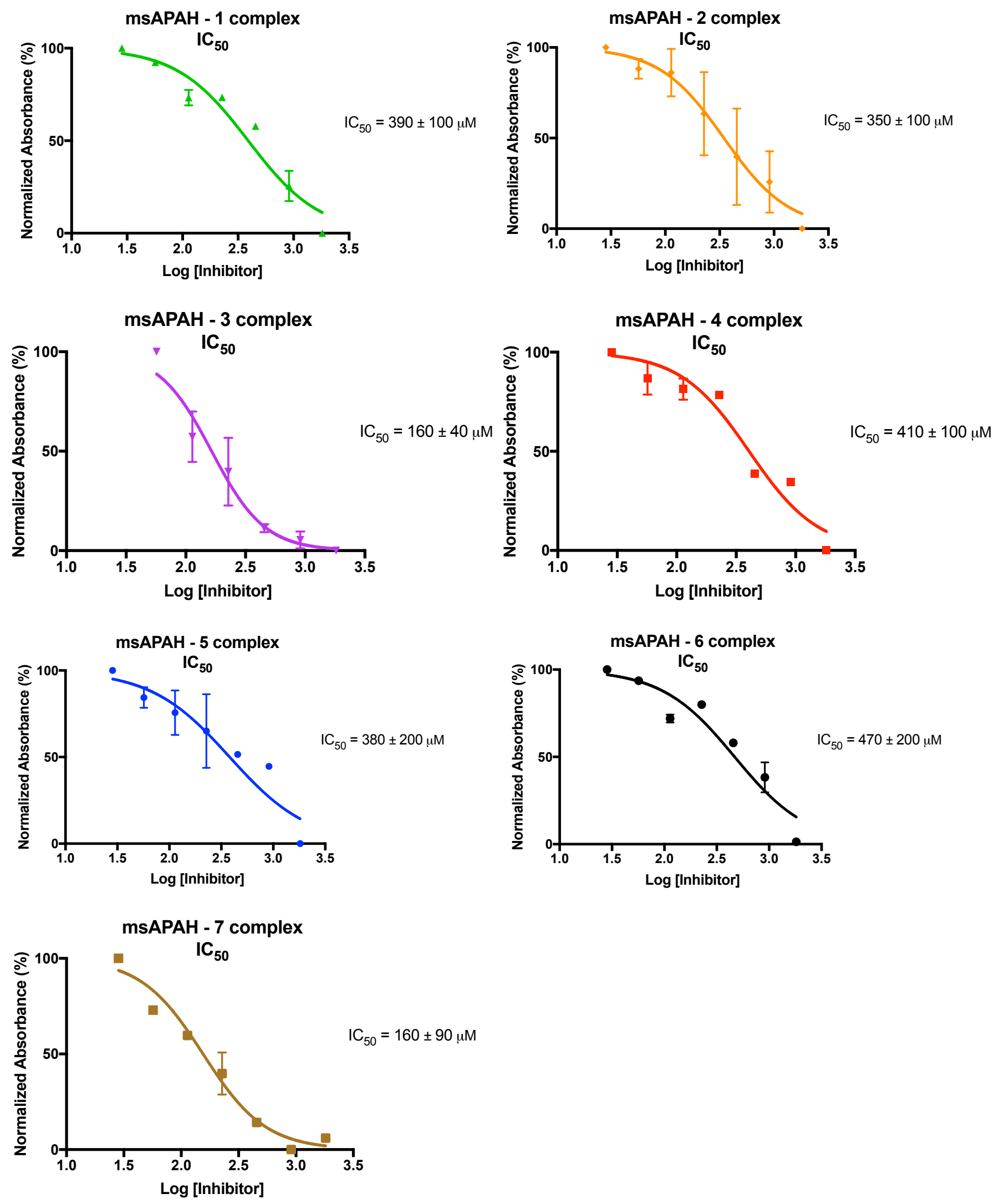

Figure S1. Measurement of inhibitory potency $\left(\mathrm{IC}_{50}\right)$ against msAPAH for compounds 1-7 based on the generation of coproduct acetate from substrate acetylcadaverine. 
(a) Inhibitor 1.

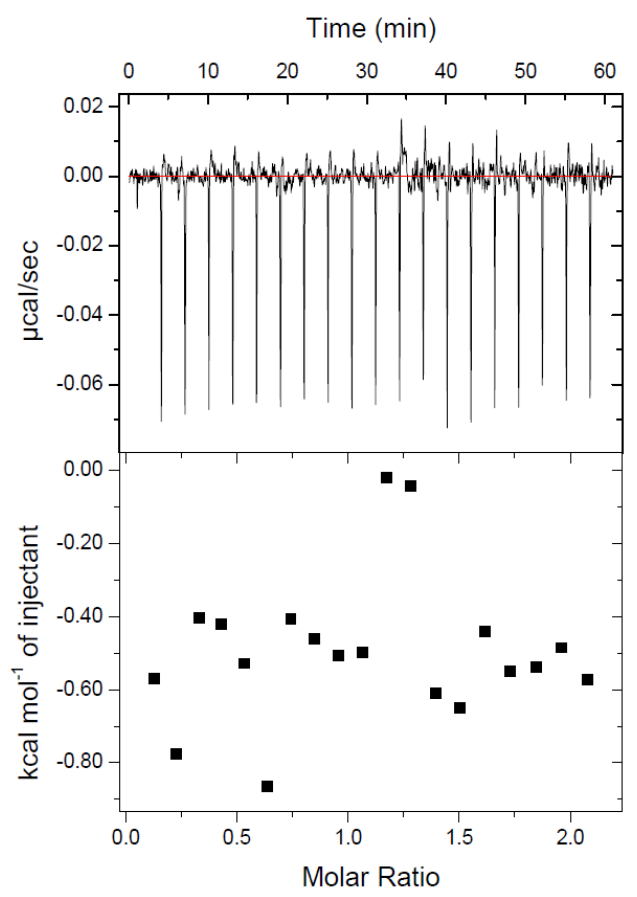

(c) Inhibitor 3.

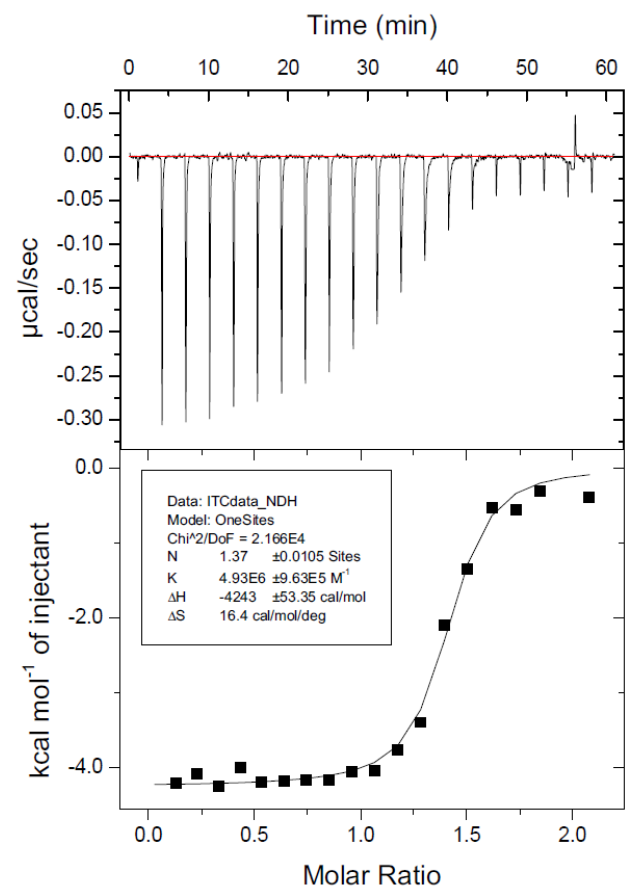

(b) Inhibitor 2.

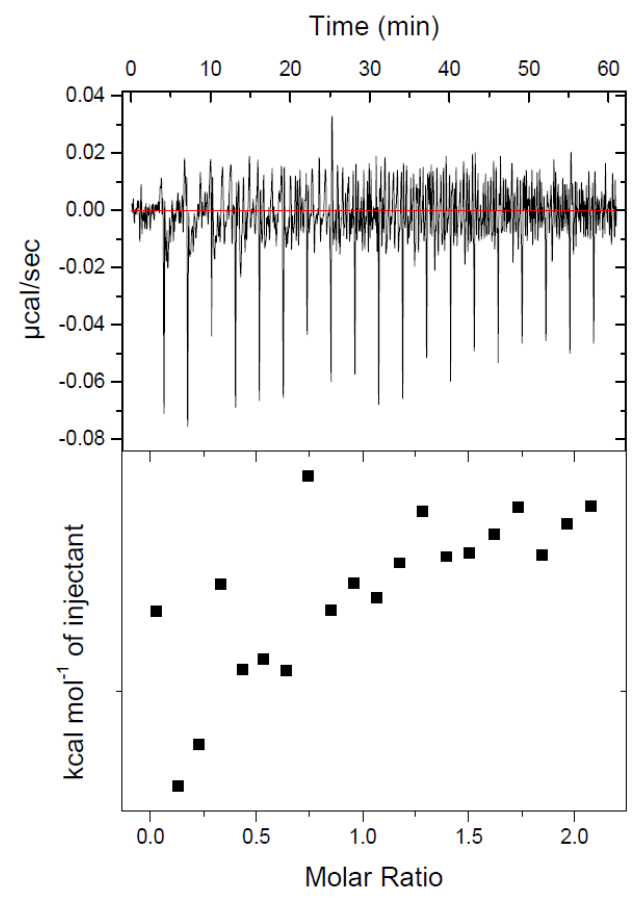

(d) Inhibitor 4.

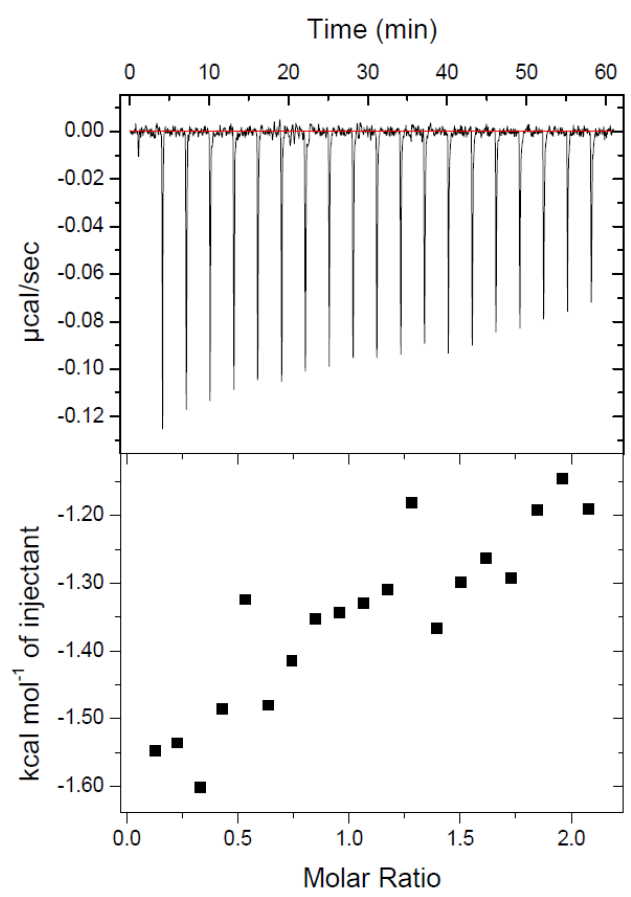


(e) Inhibitor 5.

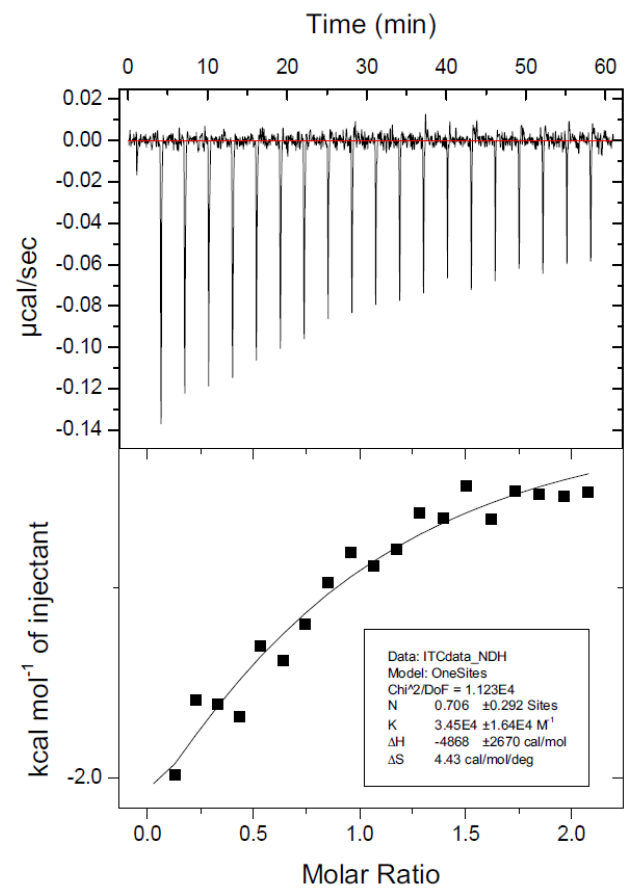

(g) Inhibitor 7.

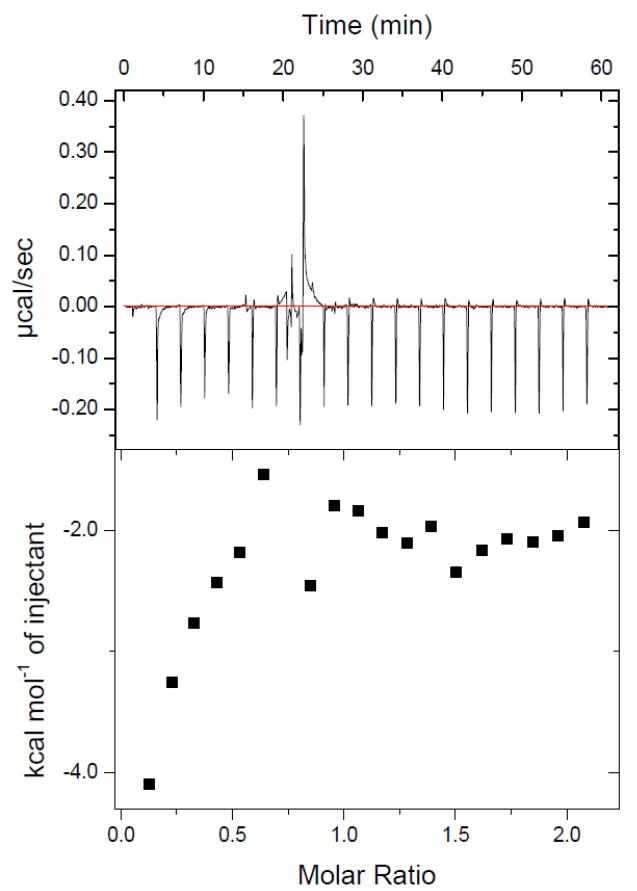

(f) Inhibitor 6 .

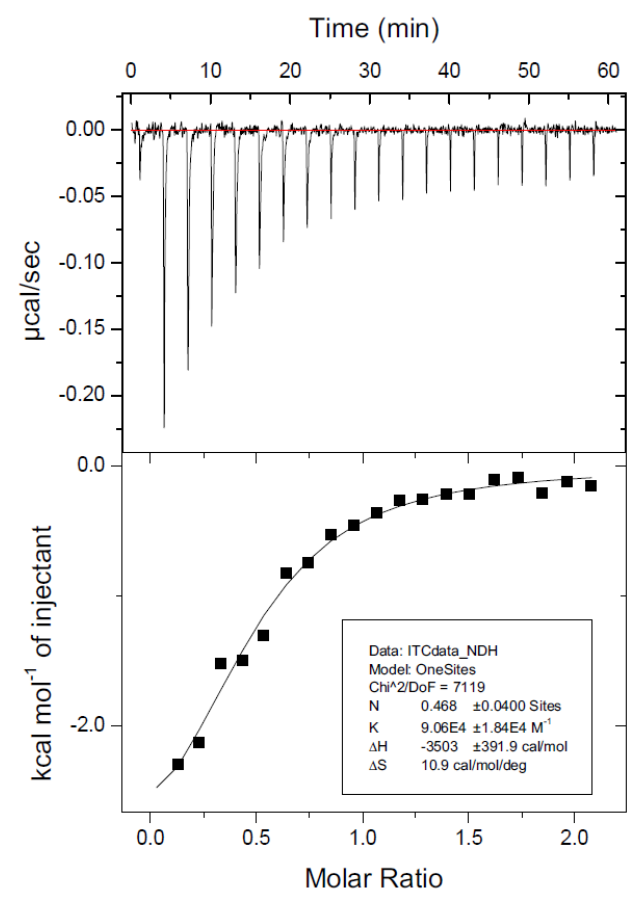

